\title{
Rainfall—runoff model performance suggests a change in flow regime and possible lack of catchment resilience
}

\author{
$\underline{\text { Richard P Silberstein }^{a},}$ Santosh K Aryal ${ }^{\mathrm{b}}$, Michael Braccia ${ }^{\mathrm{c}}$ and Jacqui Durrant ${ }^{\mathrm{c}}$ \\ ${ }^{a}$ CSIRO Land and Water, Underwood Ave, Floreat, WA, 6014 \\ ${ }^{b}$ CSIRO Land and Water, Acton, ACT, 2601 \\ ${ }^{c}$ Department of Water, Perth, WA \\ Email: Richard.Silberstein@csiro.au
}

\begin{abstract}
Climate change over the last four decades has resulted in a significant decline in streamflow in south-west Western Australia. In many streams in the region flows have reduced and perennial streams have become ephemeral. This has been accompanied by a decline in groundwater levels. To study this, a suite of five rainfall-runoff models was calibrated against observed flow in 106 gauged catchments across the region. A linear combination of two models, Sacramento and IHACRES, consistently resulted in a better model fit than any other combination of the individual models and this 'adopted model' was used to study catchment behaviour. In many of the catchments, there was a systematic and pervasive drift in model error during the latter period, indicating a change in state in the catchments that was not captured by the models. An assessment of the suitability of model structure is made on the basis of these results.
\end{abstract}

Keywords: Rainfall-runoff modelling, non-stationarity, south-west Western Australia, Sacramento, IHACRES 


\section{INTRODUCTION}

The impact of climate change on water resources has been more significant in south-west Western Australia than in many parts of the world (Hennessy et al., 2007). Since the mid-1970s, rainfall in the region has declined $16 \%$ below its long-term average, and streamflow to the water supply reservoirs in the region has reduced by well over 50\% (Petrone et al., 2010; Silberstein et al., 2012). The water management agencies are therefore keenly interested in projections of future rainfall and the impact these may have on future water resources. To explore these impacts associated with global warming, a selection of rainfall—runoff models was run with inputs from downscaled projections of global climate models (GCMs) (Silberstein et al., 2012).

The climate change over the last few decades has raised the possibility that these catchments may not be in a consistent hydrologic state through this time. Additionally, these catchments are managed for timber harvesting and mining, as well as for water reservoirs. There has been conjecture as to whether the decline in streamflow in the region was due only to the decline in rainfall or partly due to historical forest management (Silberstein and Van Niel, 2009), as almost all these catchments have actively managed commercial forests as the primary land cover. The runoff coefficient in these catchments has diminished over this period, suggesting a change of hydrological state, or at least a change in the balance of hydrological processes that may be influenced by changing rainfall, potential evaporation and/or changing forest density and structure. This also has implications for ecosystems dependent on consistent streamflows and thus for the resilience of these areas against future climate induced stresses.

This paper presents the results of an investigation into the status of these catchments by analysing the behaviour of five rainfall - runoff models. The models have different structures and different levels of complexity, from relatively simple time series transfer function to a more complete model with some hydrological process representation. By assessing the simulation performance of the models through time we may learn something about whether they are in a stationary state or not, that is whether the hydrologic 'rules' consistently apply. Understanding the causes of the observed changes in runoff response may assist future management, either to alleviate the response or to improve future projections and assist future water resource planning and catchment management.

\section{METHODOLOGY}

\subsection{Conceptual rainfall—runoff models}

Two key criteria were used to select the models. Firstly, the models should have different structures to ensure that, as far as possible, the results obtained were due to the responses being investigated rather than any particular attribute of the model. Secondly, it was important that they could be run in an automated optimisation framework to ensure that all had the same optimisation procedure and because to undertake a manual calibration on more than a few catchments would be prohibitively slow and limit the generality of the findings. Five models were tested (IHACRES, Jakeman et al. (1990); AWBM, Boughton (2004); SMAR, Goswami et al. (2002); SIMHYD, Chiew et al. (2005) and Sacramento (Burnash et al., 1973)) and the two best performing (IHACRES and Sacramento) were selected for this analysis (Silberstein and Aryal, 2013).

\subsection{Catchment selection}

The models were calibrated on 106 gauged catchments distributed across the south-west of Western Australia (Figure 1). The data were supplied by the Department of Water, WA, and covered catchments ranging in area from 10 to just under $4,000 \mathrm{~km}^{2}$. Average annual rainfall across the region ranges from $350 \mathrm{~mm}$ in the north to over $1200 \mathrm{~mm}$ in the central and southern higher elevation areas. Because of the reduction in rainfall and runoff after 1974, relative to that previously, only data from this period to 2007 were used, and all selected catchments had more than 10 years of good streamflow record in this period.

\subsection{Model calibration and selection of an 'adopted ensemble model'}

An automated optimisation framework was developed specifically for this project to enable fast, parallel processing and unbiased optimisation. The objective function used was the modelling efficiency of Nash and Sutcliffe (1970) (abbreviated as NSE) with the limitation of 5\% bias (the difference between modelled and observed flow) on the total result. Three optimisation algorithms were used, genetic, shuffle complex evolution, and uniform random sampling, each followed by the Rosenbrock local optimisation. These models have often been used without an initial 'spin up' period on the assumption that each dry season they 'reset' to an effectively dry condition. However, this assumption needed to be tested as, if the models return to the same condition each summer and the catchments do the same there would be no temporal drift in model 
performance and we could conclude that the catchments are in a stationary state climatically; we could therefore presume they were resilient under annual climate variability. Although not shown here due to space limitations, tests showed that in some catchments spin-up in excess of 10 years was necessary, and hence 15 years spin-up was set for all catchments (Silberstein et al., 2010).

(a)

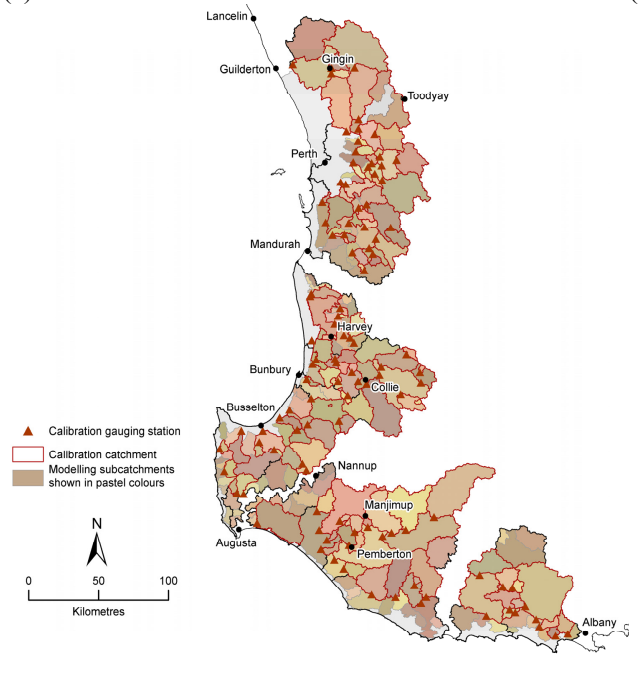

(b)

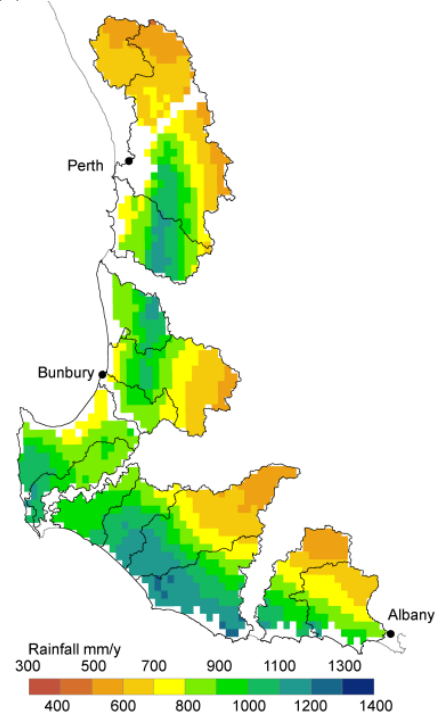

(c)

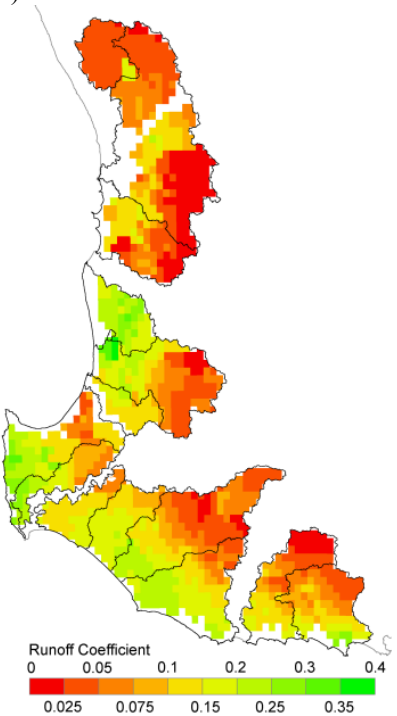

Figure 1 (a) Locations of the stream gauges, (b) distribution of rainfall and (c) runoff coefficient across south-west Western Australia used for this study

To develop the most robust model representation of the catchments, an ensemble approach was used. All five models were calibrated on all 106 stream gauges and then daily NSE was calculated for all 31 simple linear combination averages against the observed sequence. The average of Sacramento and IHACRES was selected (Silberstein and Aryal, 2013) as the best, which was interesting as they were arguably the most complicated and the simplest of the five models, respectively.

\subsection{Detecting progression of hydrological regime and hydrological resilience}

Annual total runoff from the calibrated models was compared to the observed annual totals from the gauges, and examined for drift in model error. This was the signal used to determine stationarity, or lack of it, and hence assess the resilience of these catchments to changes in rainfall regime.

\section{RESULTS}

The ensemble model gave excellent calibration of all 106 gauges in the study area with the minimum NSE of 0.6, a median of 0.83 (Figure 2), and average bias of less than 2\% (Silberstein and Aryal, 2013; Silberstein et al 2012). Note that there was no systematic geographic trend in the model efficiency, with the northern most gauges (617058 and 617165) and two central gauges (611007 and 610003) (Figure 2) sharing the status of being the only ones with NSE below 0.7. Example comparisons of modelled annual totals against observed totals are shown in Figure 3 illustrating the excellent relationship between modelled and observed runoff.

However, the modelled errors are not uniformly distributed (Figure 4). For example, catchment 617165 shows a consistent positive error in the early part of the record and then from 1983 onwards a consistent negative error, in other words the model was over estimating the flow in the early record and under estimating in the latter years. Its neighbour, 617058, however, had the opposite behaviour, with under estimation for the first 10 years and a slight over estimation from about 1985. Gauge 617003 recorded flow downstream of both of these, with a substantial additional catchment area, and shows a period of persistent under estimation from about 1985 to 1995 , thereafter it performs well. These trends are clearer as cumulative error trends (Figure 4b) as periods of persistent over-estimation or under estimation show as periods of rising or falling trend, respectively, removing the inter-annual variability in the signal.

Results for two gauges further south are also shown, 613002 and 609002, with similar behaviour, with an under estimation in the first half of the record and over-estimation in the second half. This behaviour was noted in a number of other catchments. Because the model parameters have been optimised on the whole 
record they are necessarily selected to minimise the errors overall. If the models were well formulated for the catchments and the system met the assumption of stationarity, the model errors would be uniformly distributed about the mean (close to zero). We interpret the temporal drift as indicating a change of status in the catchment, due either to land management changes or as a response to climate conditions.

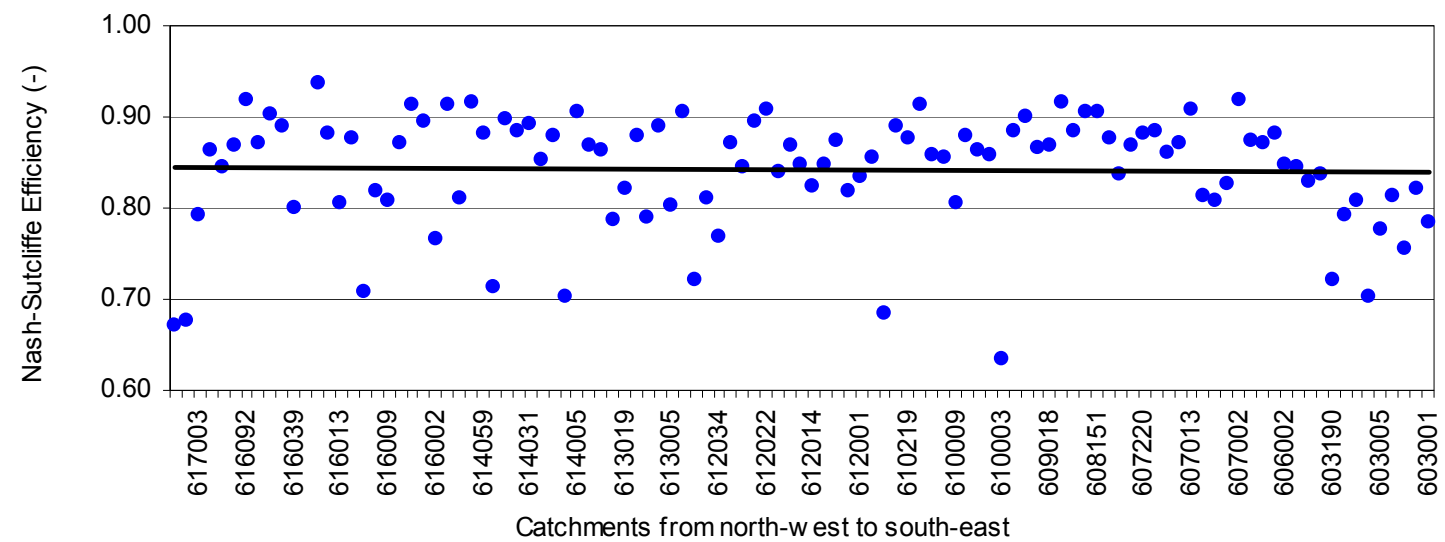

Figure 2. Daily Nash-Sutcliffe modelling efficiency for the 106 catchments (arranged in numerical order). The numbers are the Australian Water Resources Council catchment numbers. The thick line shows the median value.
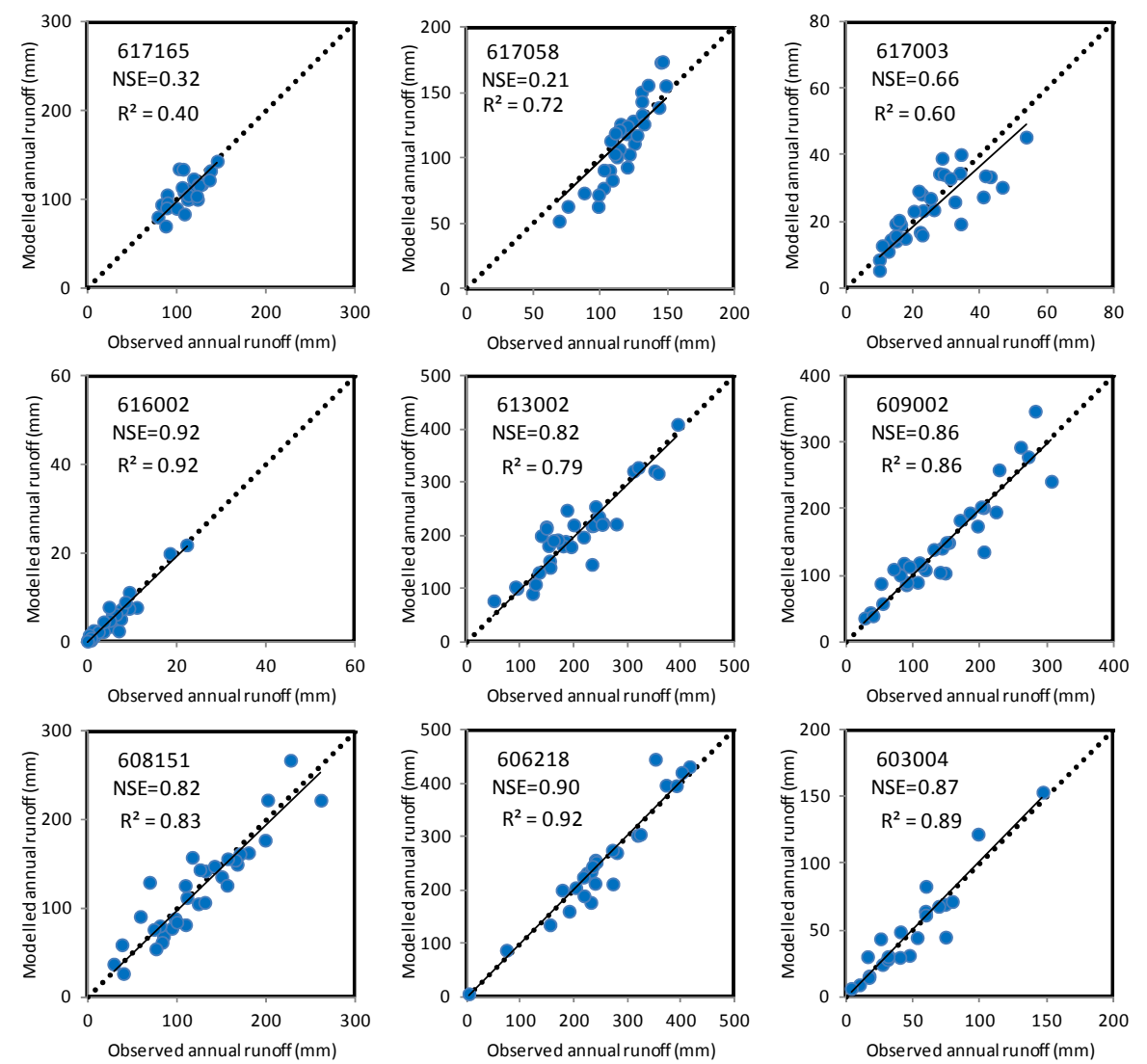

Figure 3. Modelled annual runoff plotted against observed for selected catchments. The NSEs are for the annual totals, hence are not the same is the daily values in Figure $2 ; \mathrm{r}^{2}$ are for regression forced through the origin.

\section{DISCUSSION}

The optimisations used, with objective score based on NSE and bias over the whole record, necessarily attempt to minimise the simulation errors and to distribute the errors uniformly through the measured calibration period. If the model structure captures the dominant processes and the system is stationary, then error distribution will be random in time. The fact that there are measurable trends in error in the simulations 
of the catchments presented here indicates that either the model structure is inadequate to capture the processes or some parts of the catchment system have changed, or both.

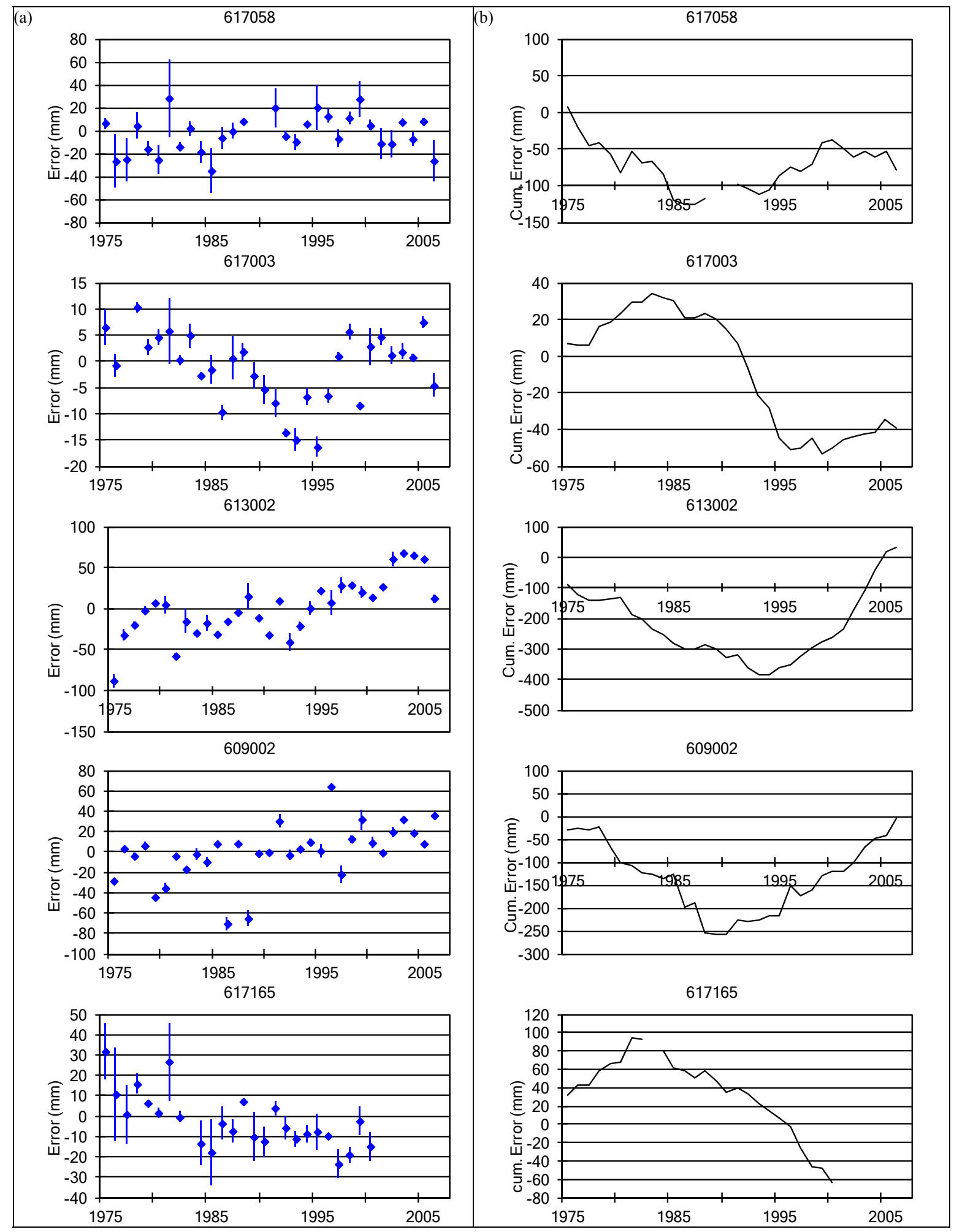

Figure 4. (a) The annual error (simulated - observed) runoff and (b) cumulative error for selected catchment gauges. Error bars indicated in (a) are the range from the composite models used in the ensemble

It is known that some changes in agriculture have occurred in the northern catchments, where the dominant land use is irrigated horticulture, mainly citrus. These orchards are irrigated with groundwater in the summer, and one element of their flow regime is that when irrigation ceases, after the crop is harvested, usually in 
February, river flow increases. This is because groundwater discharge is a significant component of the total flow, and is part of the reason that the two catchments (617165 and 617058) have the poorest modelling efficiency (as shown in Figure 2). The three northern catchments (617003, 617165 and 617058) have quite different error trends, indicating systematic differences in conditions. It is our conjecture that the second two, which are significantly smaller than $617003\left(1370 \mathrm{~km}^{2}\right)$, are more influenced by local groundwater management, and this is reflected in the lower NSE score (Figure 3).

However, most of these catchments are covered in native forest, managed for timber and water resources. There is some mining and rehabilitation in nearby catchments but this does not affect the catchments discussed here. These catchments are known to have a relatively low runoff coefficient on a world scale, attributed to the deep regolith, deep rooting character and perennial vegetation (Schofield et al., 1989). However, the continued decline in runoff generation over the last few decades is unprecedented and appears to persist in many catchments in the region (Petrone et al., 2010). Timber harvesting, when it occurs, could have a significant impact on catchment water balance, and this has been proposed as a major influence on changes in hydrologic behaviour. Indeed, the study of catchment thinning and changes to streamflow generation is mature, although still contentious (Hewlett and Hibbert, 1967; Bosch and Hewlett, 1982; Hornbeck et al., 1993; Ruprecht and Stoneman, 1993; Bari and Ruprecht, 2003).

Some of these catchments have undergone significant vegetation changes, particularly in the southern regions, with development of agroforestry and environmental plantings in the higher rainfall zones during the 1990s. In these catchments it may be expected that rapidly growing trees would use more water, and this could account for over-estimation of streamflow by models which do not include these influences, later to be replaced with under estimation as the tree water use plateaus. In contrast, the hydrological trends that have led to the fall in streamflow have been discussed by several authors (Petrone et al., 2010; Hughes et al., 2012). Whether the declining rainfall is responsible directly or indirectly through rainfall influence on other components of the hydrologic system is considered by these authors. They show that there is a direct link between the declining groundwater storage within the catchments and the change in runoff coefficient and it is this process that is likely to produce the trend in model errors. Hughes et al. (2013) discuss improvements to an existing rainfall-runoff model to include better representation of deep groundwater systems, hitherto often ignored in surface water modelling as deemed unresponsive and of little influence in surface water processes. This concept is now under significant question (Petrone et al., 2010; Hughes et al., 2012; 2013).

\section{CONCLUSIONS}

The temporal trends in model errors presented above indicate changes in state within the catchments, and show that these forested catchments are not resilient against the changes they are undergoing, primarily climate changes, as runoff characteristics are not being maintained. In the context of this paper, nonstationarity in catchment response is a reflection that either the catchments are undergoing some state changes that are not represented in the models or that the models used may not adequately represent physical processes in the catchment. Given the application of models of different structures all reproduce the same features, we conclude that there are state changes underway in these catchments, irrespective of the possible incompleteness of model structures. Runoff generation has not fundamentally changed but the balance of different processes, particularly the proportion of rainfall that evaporates, may have. This would lead to changes in runoff quantity and runoff coefficient, and hence the runoff-rainfall non-stationarity. This has occurred in catchments without a land-use change. For cases in which land use changes have occurred, namely clearing or reafforestation, these are superimposed on climate driven changes. In these cases the lack of stationarity may be temporary and the catchments may retain a resilience that our datasets are insufficient to demonstrate; longer datasets are required to confirm this. To be definitive on the causes of model error drift requires both more data and a more complete analysis of models structures. Both of these have been beyond the scope of the work described, but both are the subject of ongoing investigation. The models used in this study are all in common use in research and industry. Improvement starts with recognition there is an issue, and that is our key conclusion. The fact that it affects all of these models does not mean that all models would be subject to the same limitations, however a model capturing the drift in proportion of rainfall that becomes runoff must capture the changes in water balance partitioning, either explicitly with appropriate process representation, or serendipitously with internal compensating errors. The former is clearly the aim of hydrology, the latter likely to be an unfortunate distraction from real progress (Silberstein, 2006).

\section{ACKNOWLEDGMENTS}

This work was funded by the Australian Government through the Department of Environment, Water Heritage and the Arts. We were greatly assisted by Mark Pearcey and colleagues, in the Department of 
Water, WA, and by Steve Charles, Francis Chiew, Ang Yang, Don McFarlane, Geoff Hodgson and Olga Barron in CSIRO.

\section{REFERENCES}

Bari, M.A. and Ruprecht, J.K., 2003. Water yield response to land use change in south-west Western Australia. Salinity and Land Use Impacts Series, Report No. SLUI 31, Dept of Environment, Perth, Western Australia, 36pp.

Bosch, J.M. and Hewlett, J.D., 1982. A review of catchment experiments to determine the effect of vegetation changes on water yield and evapotranspiration. Journal of Hydrology, 55, 3-23.

Boughton, W., 2004. The Australian water balance model. Environmental Modelling \& Software, 19(10), 943-956. doi:10.1016/j.cnvsoft.2003.10.007.

Burnash, R.J.C., Ferral, R.L. and McGuire, R.A., 1973. A Generalised Streamflow Simulation System Conceptual Modelling for Digital Computers, US Department of Commerce, National Weather Service and State of California, Department of Water Resources.

Chiew, F.H.S. and Siriwardena, L., 2005. Estimation of SIMHYD parameter values for application in ungauged catchments, (MODSIM 2005), Melbourne, Australia.

Goswami, M., O'Connor, K.M. and Shamdeldin, A.Y., 2002. Structures and performances of five rainfallrunoff models for continuous river-flow simulation, 1st Biennial Meeting of International Environmental Modeling and Software Society, 1, Lugano, Switzerland, 476-481.

Hennessy, K., Fitzharris, B., Bates, B.C., Harvey, N., Howden, S.M., Hughes, L., J., S. and Warrick, R., 2007. Australia and New Zealand. Climate Change 2007: Impacts, Adaptation and Vulnerability. Contribution of Working Group II to the Fourth Assessment Report of the Intergovernmental Panel on Climate Change. In: M.L. Parry, O.F. Canziani, J.P. Palutikof, P.J. van der Linden and C.E. Hanson (Editors). Cambridge University Press, Cambridge, UK, pp. 507-540.

Hewlett, J.D. and Hibbert, A.R., 1967. Factors affecting the response of small watersheds to precipitation in humid areas. First International Symposium on Forest Hydrology. Pergamon, 275-290.

Hornbeck, J.W., Adams, M.B., Corbett, E.S., Verry, E.S. and Lynch, J.A., 1993. Long-term impacts of forest treatments on water yield - A summary for northeastern USA. Journal of Hydrology, 150(2-4), 323344. doi:10.1016/0022-1694(93)90115-p.

Hughes, J., Silberstein, R. and Grigg, A., 2013. Extending rainfall-runoff models for use in environments with long-term catchment storage and forest cover changes, MODSIM 2013. Modelling and Simulation Society of Australia and New Zealand, Adelaide.

Hughes, J.D., Petrone, K.C. and Silberstein, R.P., 2012. Drought, groundwater storage and stream flow decline in southwestern Australia. Geophysical Research Letters, 39, L03408. doi:doi:10.1029/2011GL050797.

Jakeman, A.J., Littlewood, I.G. and Whitehead, P.G., 1990. Computation of the instantaneous unit hydrograph and identifiable component flows with application to two small upland catchments. Journal of Hydrology, 117, 275-300.

Nash, J.E. and Sutcliffe, J.V., 1970. River flow forecasting through conceptual models. Part 1 - A discussion of principles. Journal of Hydrology, 10, 282-290.

Petrone, K.C., Hughes, J.D., Van Niel, T.G. and Silberstein, R.P., 2010. Streamflow decline in southwestern Australia, 1950-2008. Geophysical Research Letters, 37(11), 11401. doi:10.1029/2010GL043102R.

Ruprecht, J.K. and Stoneman, G.L., 1993. Water yield issues in the jarrah forest of south-western Australia. Journal of Hydrology, 150(2-4), 369-391.

Schofield, N.J., Stoneman, G.L. and Loh, I.C., 1989. Hydrology of the Jarrah forest. In: B. Dell, J.J. Havell and N. Malajczuk (Editors), The Jarrah Forest - A complex mediteranean ecosystem, Chap. 12. Kluwer Academic Publishers, pp. 179-201.

Silberstein, R.P., 2006. Hydrological models are so good, do we still need data? Environmental Modelling and Software, 21(9), 1340-1352.

Silberstein, R.P. and Aryal, S.K., 2013. Assessing the performance of an ensemble approach to rainfall runoff modelling for prediction of climate change, MODSIM 2013. The Modelling and Simulation Society of Australia and New Zealand, Adelaide, this volume.

Silberstein, R.P., Aryal, S.K., Durrant, J., Pearcey, M., Charles, S., Braccia, M., Boniecka, L., Hodgson, G.A., Bari, M.A., Viney, N.R. and McFarlane, D.M., 2012. Climate change and runoff in southwestern Australia. Journal of Hydrology, 475, 441-455. doi:doi:10.1016/j.jhydrol.2012.02.009.

Silberstein, R.P. and Van Niel, T., 2009. What is the connection between long-term changes in rainfall and stream flow in catchments in south-west Western Australia?, Greenhouse 2009, Perth. 